\title{
Tail-anchored membrane protein insertion into the endoplasmic reticulum
}

\author{
Ramanujan S. Hegde ${ }^{1}$ and Robert J. Keenan ${ }^{2}$ \\ ${ }^{1}$ MRC Laboratory of Molecular Biology, Hills Road, Cambridge CB2 OQH, UK \\ ${ }^{2}$ Department of Biochemistry and Molecular Biology, The University of Chicago, Gordon Center \\ for Integrative Science, Room W238, Chicago, IL 60637, USA
}

\section{Abstract}

Membrane proteins are inserted into the endoplasmic reticulum by two highly conserved parallel pathways. The well-studied co-translational pathway uses the signal recognition particle and its receptor for targeting, and the Sec61 translocon for membrane integration. A recently discovered post-translational pathway uses an entirely different set of factors involving transmembrane domain-selective cytosolic chaperones and an accompanying receptor at the endoplasmic reticulum. Elucidation of the structural and mechanistic basis of this post-translational membrane protein insertion pathway highlights general principles shared between the two pathways and key distinctions unique to each.

\begin{abstract}
All biological membranes contain a structurally diverse range of integral membrane proteins that collectively comprise $\sim 30 \%$ of the cellular proteome $e^{1,2}$. These proteins impart essential functionality to the lipid bilayer to allow a range of cellular activities including transmembrane communication, transport, and membrane morphogenesis. Selective and asymmetric insertion of membrane proteins is therefore an evolutionarily ancient problem solved by the earliest life forms.
\end{abstract}

The shared feature of all integral membrane proteins is the highly hydrophobic transmembrane domain (TMD), which in the final structure resides within the lipid bilayer ${ }^{3}$. Thus, a critical obstacle in membrane protein insertion is the movement of these TMDs from the aqueous cytosol, where they are synthesized, into the lipid bilayer, where they are energetically most stable ${ }^{4}$. This process necessitates selective TMD recognition, TMD shielding from the aqueous cytosol, targeting to the membrane surface, and TMD integration into the lipid bilayer in the correct orientation. All membrane insertion pathways must solve these four problems, each of which typically involves specialized and highly regulated factors in the cytosol and target membrane.

In eukaryotes, membrane proteins synthesized on cytosolic ribosomes can be targeted to mitochondria ${ }^{5}$, peroxisomes ${ }^{6}$, chloroplasts (in plants) ${ }^{7}$, and the endoplasmic reticulum $(\mathrm{ER})^{8}$. Among these, the ER accommodates the largest number of clients, encompassing all membrane proteins of the plasma membrane, compartments of the secretory and endocytic pathways, and both nuclear envelope membranes ${ }^{9}$.

Insertion into the ER membrane can occur either co-translationally or post-translationally, each of which offers distinct advantages ${ }^{10,11}$. In the co-translational pathway, all of the steps

The Keenan group homepage: http://keenanlab.bsd.uchicago.edu/

The Hegde group homepage: http://www2.mrc-lmb.cam.ac.uk/group-leaders/h-to-m/r-hegde 
from initial recognition to final membrane insertion occur during protein synthesis. By contrast, targeting and insertion via post-translational pathways occur after complete synthesis of the membrane protein substrate. Thus, the ribosome is a major functional component during all steps of co-translational insertion, whereas its role in post-translational pathways is limited to the very earliest steps.

Although the co-translational pathway was discovered over 30 years ago ${ }^{12-14}$ and has been extensively studied in many systems ${ }^{15-19}$, the post-translational insertion pathway has only recently come into focus. Similarly to post-translational translocation of soluble proteins into various organelles ${ }^{20-24}$, the basic paradigm of post-translational ER membrane protein insertion involves cytosolic chaperones (mediating recognition and shielding) that interact with a specific ER-localized receptor (mediating targeting and insertion). Here, we review this post-translational pathway, and discuss how the problems of recognition, shielding, targeting, and insertion are solved by its machinery. As we will outline, there is now sufficient information about each step to provide a plausible mechanistic framework for the whole pathway. These insights are starting to reveal common themes that are likely to apply to all membrane insertion processes.

\section{The co-translational pathway}

The extensively studied co-translational pathway provided an important conceptual context to understand post-translational membrane protein insertion. It is therefore worth first summarizing the general features of co-translational membrane protein insertion $8,11,25,26$. This pathway begins when a hydrophobic segment of the protein, typically the first transmembrane domain (TMD), emerges from the ribosome (FIG. 1). This hydrophobic domain is recognized by the signal recognition particle $(\mathrm{SRP})^{27}$, a large ribonucleoprotein complex composed of multiple proteins and an RNA scaffold ${ }^{28}$. SRP has a high affinity for ribosomes, and binds through its $54 \mathrm{kD}$ subunit (SRP54) near the ribosomal exit tunnel ${ }^{29}$. The methionine-rich M-domain of SRP54, which directly binds to hydrophobic domains ${ }^{30,31}$, is therefore precisely poised to capture the nascent membrane protein.

After this initial recognition step, the SRP-bound ribosome-nascent chain complex (RNC) is targeted to the SRP receptor ${ }^{32,33}$ at the ER membrane. The RNC is then released from SRP and transferred to the Sec61 complex, the central component of a protein translocon in the $\mathrm{ER}^{16,34,35}$. The ribosome subsequently completes synthesis of the membrane protein while remaining bound to the Sec61 translocon. The Sec61 complex is therefore positioned to recognize each TMD as it emerges from the ribosome and facilitate their integration into the lipid bilayer ${ }^{36-38}$.

A major advantage of the co-translational strategy is that the machinery for targeting and insertion is physically coupled to the ribosome near the polypeptide exit tunnel. This spatial organization allows TMDs to be recognized, shielded, and inserted with minimal exposure to the bulk cytosol. The co-translational insertion machinery therefore enjoys a considerable competitive advantage in binding to TMDs among many other potential binding partners in the cell.

More importantly, especially for multi-spanning membrane proteins, the handling of TMDs as they emerge from the ribosome substantially obviates a need to maintain solubility of highly hydrophobic, lengthy, and complicated proteins. Because the machinery for TMD insertion is the same as that which mediates translocation of soluble proteins, membrane proteins with large soluble domains that undergo translocation do so by the co-translational pathway. Thus, a near-universal theme is that membrane proteins with multiple TMDs or large translocated domains employ the co-translational mode of translocation. These proteins constitute the majority of membrane proteins in the cell and co-translational 
membrane protein insertion has been described for the ER, the topologically equivalent bacterial plasma membrane ${ }^{39}$, mitochondrial inner membrane ${ }^{40}$, and thylakoids of chloroplasts $^{41}$. The Sec61 complex also mediates post-translational translocation of soluble proteins in both bacteria and eukaryotes ${ }^{10,11}$; as this pathway is not known to mediate membrane protein insertion, it will not be considered in this review.

\section{Discovery of a new insertion pathway}

As the SRP-dependent pathway was being elucidated, it became clear that at least some membrane proteins might not be able to use this route for insertion. In particular, the apparently obligate recognition of membrane proteins by SRP during synthesis was noted to be incompatible with proteins whose sole TMD resides near the C-terminus ${ }^{42}$. This is because the TMD would be inside the ribosomal tunnel (which houses $\sim 40$ amino acids of the nascent polypeptide) when the termination codon was reached. This necessarily requires that TMD recognition occurs after termination of translation, and hence post-translationally.

Among the first of these 'tail-anchored' (TA) proteins to be examined for its SRPdependence was synaptobrevin - a SNARE protein that has key roles in intracellular vesicular trafficking. It was rigorously demonstrated that as predicted, synaptobrevin uses an SRP- and Sec61-independent post-translational pathway for its insertion into the $\mathrm{ER}^{43}$. Although this and subsequent studies showed that insertion was protein- and ATPdependent ${ }^{43-46}$, the molecular basis of this energy requirement or the factors involved in insertion remained obscure for over ten years.

During this intervening period, TA proteins were increasingly appreciated to be of broad physiological importance. Representing $\sim 3-5 \%$ of all membrane proteins ${ }^{47-49}$, TA proteins are found in all cellular membranes and have functions that range from membrane biogenesis, apoptosis and vesicular trafficking, to protein degradation, and many others. With increased interest in this class of proteins, greater attention was paid to their mechanism of insertion. However, studies of different TA proteins by different methods led to diverse conclusions. This ranged from proposals of an unassisted mechanism not requiring any insertion machinery (for cytochrome b5 studied in vitro) ${ }^{44,50,51}$, to an Hsp70mediated pathway ${ }^{52}$, to one utilizing SRP and Sec61 in a post-translational mode ${ }^{53,54}$. The physiological relevance of these potential routes to the membrane remain largely unclear at present (BOX 1).

\section{Box 1}

\section{Other routes into the ER membrane}

In the absence of the GET/TRC system, many TA proteins are still able to insert into a membrane in vitro and in vivo with at least some efficiency. This raises the possibility of additional pathways for TA protein insertion into the ER including an unassisted pathway ${ }^{44,50,51}$, a chaperone-mediated pathway involving $\mathrm{Hsp} 70^{52}$, and a pathway using SRP in a post-translational mode ${ }^{53}$. The mechanisms of these possible routes will not be considered here in detail. Nevertheless, it is worth considering whether these are bona fide insertion pathways that are normally operational in vivo.

Several observations suggest that these may be ad hoc insertion mechanisms, only detectable under specialized conditions. First, deletion of GET components in Saccharomyces cerevisiae produces TA proteins that are substantially aggregated and/or mis-localized ${ }^{65,66,116}$. Thus, although enough essential TA proteins do manage to insert into the ER to maintain viability, target specificity and insertion efficiency are compromised for all substrates that have been examined. Second, essentially all of the evidence for these pathways derives from in vitro analyses which use one membrane, so 
that targeting specificity is not assayed. Although these systems are powerful, interpretation of in vitro studies merits some caution in the absence of further corroboration. Additionally, the use of crude translation lysates and microsomes pose a substantial problem for interpretation because it is now clear that they contain the GET/ TRC targeting machinery 55,66 . Even if cytosol is replaced by purified factors ${ }^{52}$, addition of microsomes contributes substantial amounts of the GET/TRC machinery (including Get3/TRC40). Thus, any factors that can temporarily prevent TA proteins from aggregation may seem to be necessary simply by facilitating capture by the GET/TRC pathway. And finally, in vitro crosslinking assays (the primary means of detecting potential targeting factors) can lead to numerous minor off-pathway interactions given the rather hydrophobic TA substrate and lengthy reaction times. Thus, while it is possible other specific pathways exist, their rigorous validation and demonstration of physiological importance awaits additional studies.

Eventually, biochemical analysis of TA protein insertion in cell-free translation extracts, combined with protein crosslinking approaches, led to the identification of a factor that associated with the TMDs of TA proteins (FIG. 1) ${ }^{55,56}$. This factor, originally annotated Asna $^{57}$ (for its similarity to ArsA, an arsenite-transporting ATPase in bacterial systems ${ }^{58}$ ), was re-named TRC40 for TMD-recognition complex protein of $40 \mathrm{kD}$. Evidence for its role in TA insertion came from several in vitro observations ${ }^{55,56}$, each of which was eventually explained by subsequent mechanistic studies.

First, TRC40 associated with the TMDs of TA proteins, but not membrane proteins with internal TMDs ${ }^{55,56}$. Second, it was an ATPase (which reconciled the original ATPdependence of TA protein insertion). Third, it was highly conserved across all eukaryotes, was essential in mammals ${ }^{59}$, and phenotypes in other organisms were related to processes that involved TA proteins ${ }^{60-62}$. Fourth, an ATPase-deficient mutant acted as a dominantnegative, selectively binding to but not releasing TA proteins, thereby precluding their membrane insertion ${ }^{55}$. Fifth, a fraction of TRC40 was found on the ER membrane, and this could be released by ATP ${ }^{55}$. And finally, it contained a proteinaceous binding site(s) on ER microsomes ${ }^{55}$. Based on these observations, TRC40 was proposed to be a targeting factor that selectively recognizes TA proteins in the cytosol and delivers them to the ER for insertion in an ATP-dependent manner ${ }^{55}$.

The high level of conservation readily identified a protein called Get3 (originally called Arr $4^{63}$, again due to its similarity to ArsA) as the budding yeast homologue. Synthetic genetic- and physical interaction studies had already defined Get3 as part of a pathway involving at least two other genes (termed Get1 and Get2), the loss of which led to phenotypes that were consistent with a role in Golgi-to-ER trafficking (and hence, the acronym GET) $60,61,64$. However, the physical and functional links of the mammalian homologue to TA protein insertion, combined with the fact that Golgi-to-ER trafficking depends on TA proteins, led to a re-assessment of the Get pathway. Parsimoniously, all of the otherwise unconnected yeast phenotypes associated with the Get pathway were reconciled as secondary to defects in TA insertion, meriting a change to the 'guided entry of TA proteins' moniker for the GET genes ${ }^{65}$. Subsequent physical and genetic interaction analysis of this GET pathway in yeast led to the identification of three additional factors (termed Get4, Get5, and Sgt2) 66,67 . This defined the major players in a single experimental system of budding yeast and placed them into either early (cytosolic for Get3, Get4, Get5, and Sgt2) or late (membrane for Get1, Get2, and Get3) steps that made genetic sense. Subsequent insights into the mechanistic roles of these factors have come from a combination of structural and functional studies, primarily of the yeast GET pathway. 


\section{Substrate recognition by Get3}

Critical to TA protein targeting is its selective and efficient recognition by Get3. The sensitivity of this interaction to detergent and its dependence on the presence of a functional TMD strongly suggested a direct recognition of the TMD via hydrophobic interactions with Get ${ }^{55}$. Such a direct interaction could also shield and maintain the solubility of the hydrophobic TMD as it transits through the cytosol. Insight into both TA substrate recognition and shielding came from structural studies.

Near-simultaneous reports of Get 3 crystal structures from multiple fungal species and in multiple states revealed that Get3 was a symmetric homodimer ${ }^{68-72}$. Each Get3 monomer comprises a core ATPase domain decorated with an a-helical domain. The arrangement of Get3 subunits depends on the nucleotide state, transitioning from a fully open state in the absence of nucleotide, to a fully closed conformation in the presence of $\mathrm{Mg}^{2+} \mathrm{ADP} \bullet \mathrm{AlF}_{4}{ }^{-}$ (which seems to mimic the ATP-bound state), and to a partially closed state in the presence of $\mathrm{Mg}^{2+} \mathrm{ADP}$ (FIG. 2). In contrast with the relatively rigid conformation of the ATPase domain, the conformation of the a-helical domain is sensitive to nucleotide binding. In the fully closed, ATP-bound state, the helical subdomains are in direct contact, and define a large, hydrophobic groove that spans both Get3 monomers (FIGS. 2 and 3) ${ }^{70}$.

Three lines of evidence illustrated that the helical domains mediate recognition. First, the size, shape, hydrophobicity, flexibility, and the ATP-dependent formation of the composite groove argued for this being the site of TMD binding ${ }^{68-71}$. Second, hydrogen exchange mass spectrometry (HX-MS) studies demonstrated protection of the a-helical subdomains upon binding to a TA substrate ${ }^{68}$. Third, perturbing the composite hydrophobic groove by introducing negative charges or disrupting dimerization reduced TA substrate binding in vitro, and led to growth defects in vivo ${ }^{70}$.

The process of substrate recognition in the co- and post-translational pathways shows important functional and mechanistic similarities. As with Get3, the recognition element in Ffh (the bacterial SRP54 homologue) is constructed from an a-helical protein scaffold that presents a large hydrophobic surface area for substrate binding (FIG. 3) ${ }^{73}$. Moreover, these scaffolds are highly dynamic. As two crystal structures of the SRP54-signal peptide complexes show, this flexibility can be leveraged to accommodate targeting signals of different lengths and sequence ${ }^{74,75}$. A similar mechanism is probably at play in the case of Get3, although this awaits further structural analysis of Get3-TMD complexes.

In addition to flexibility in accommodating different sequences, substrate recognition by Get3 must also be selective in at least two ways. First, the C-terminal TMDs of TA proteins must be distinguished from the internal TMDs of co-translational substrates. Second, Get3 must avoid the TMDs of TA proteins destined for other organelles (such as peroxisomes, mitochondria, and chloroplasts). As there is little difference between the TMDs of these different substrates ${ }^{76}$, a key issue is how the GET pathway selects only the correct substrates for targeting.

One clue comes from the observation that in the absence of SRP (or other competing factors), Get 3 can bind substrates containing internal TMDs. Conversely, SRP cannot recognize a TMD it normally binds when that same TMD is near the C-terminus. This suggests that under physiological conditions, SRP has a strong advantage for association with internal TMDs by its interaction with a translating ribosome. Hence, its very high local concentration near the ribosomal exit tunnel ensures that SRP will out-compete any available binding proteins such as Get3. 
Distinguishing ER-destined TA proteins from other TA proteins is a more difficult problem because they cannot be discriminated on the basis of topological constraints. In vitro crosslinking studies in mammalian translation extracts show a clear dependence on hydrophobicity for TRC40 association, with even modest decreases abolishing the interaction ${ }^{77}$. But it is difficult to envision how the flexible hydrophobic groove of TRC40/ Get 3 could, by itself, provide tight discrimination between closely related TA substrates. Instead, as described below, additional co-factors acting in conjunction with TRC40/Get3 probably enhance fidelity of substrate recognition.

\section{Co-factors for substrate loading}

Although the structure of Get3 explained how it could bind and shield the TMD of a TA protein, it was unclear how the TA protein could get loaded onto Get3 in the first place. At least three issues were especially problematic. First, Get3 did not appear to bind ribosomes, raising the problem of how it could capture TA proteins after their release from the ribosome in a sufficiently timely manner to avoid inappropriate interactions and aggregation. Second, it seemed unlikely that the conformation of Get3 that binds TA proteins, which exposes a large hydrophobic surface, would be favoured or long-lived in the aqueous cytosol. Third, it was unclear how Get3 could out-compete other chaperones in the cytosol that also bind hydrophobic domains. Thus, a gap existed between TA protein release from the ribosome and subsequent recognition by Get3.

Genetic analysis in budding yeast had suggested that cytosolic co-factors Get4, Get5 and Sgt2 affected this process, although it was unclear how ${ }^{66,67}$. Insight into this problem came from parallel biochemical studies in the yeast and mammalian systems that converged in supporting a conserved role for pre-targeting co-factors in aiding substrate capture by Get3 (FIG. 4). In yeast, Sgt2 was observed to bind directly to the TMDs of TA proteins, and this interaction was critical for their loading onto Get $3^{78}$. Importantly, transfer of TA proteins from Sgt2 to Get3 required the Get4-Get5 subcomplex. Interaction analysis further showed that Get4-Get5 forms a scaffold that bridges Sgt2 (which binds to Get5) and Get3 (which binds to Get4). Importantly, Get4 may favour binding selectively to the ATP-bound (and hence 'closed') conformation of Get $3{ }^{79}$. This means that Get3 is recruited to Get4-Get5 selectively in a conformation that exposes its hydrophobic TMD binding groove. Thus, an attractive model is that substrates are transferred from Sgt 2 to Get 3 through the ability of Get4-Get5 to selectively recruit the correct conformation of Get3 in proximity to substratebound Sgt2. Precisely how this intricate handover occurs remains to be investigated.

A similar process seems to operate in the mammalian system ${ }^{77}$. In this case, an assay for substrate capture by TRC40 was used to illustrate the need for other factors. Purification of a requisite factor revealed a three protein complex composed of Bag6 (also called Bat 3 or Scythe), TRC35, and Ub14A. The latter two are homologous to Get4 and Get5, respectively, and the former can interact with TA proteins, similarly to Sgt2 (although no primary sequence homology is apparent). Depletion of the Bag6 complex resulted in defective TA protein capture by TRC40, and reduced membrane insertion efficiency. Thus, by homology and by functional analysis, pre-targeting co-factors facilitate substrate loading onto Get 3 and TRC40 in the yeast and mammalian systems, respectively.

Although mammalian Bag6 and yeast Sgt2 are not related, it is noteworthy that Bag6 interacts with SGTA, the mammalian homologue of Sgt2. This suggests a more parsimonious model in which the yeast and mammalian systems are even more similar than previously thought (FIG. 4). In both systems, Get4-Get5 (plus the tightly bound Bag6 in the mammalian system) is the scaffold that dynamically brings Sgt2/SGTA into close proximity with Get3/TRC40. This large and transient assembly is loosely defined as the 'TMD 
recognition complex' (TRC), within which a substrate would be sorted among these factors. A committed targeting complex would be generated only if the substrate binds productively with Get3/TRC40, a fate favoured by ER-destined TA proteins. If the substrate is unsuitable for ER targeting, it would be transferred to other factors that impart alternative fates. These might include chaperones that are specific for other destinations, such as the mitochondria, or quality control factors that mediate degradation. Indeed, recent work suggests that Bag6 is precisely such a quality control factor that can bind a variety of hydrophobic substrates, recruit an E3 ubiquitin ligase, and route them for proteasomal degradation ${ }^{80-82}$.

Thus, the picture that is emerging is one of initial hydrophobic protein capture at the ribosome, followed by assembly into a highly dynamic sorting complex (the TRC) containing many potential binding partners. The substrate would then partition among the binding partners, with the final outcome depending on the specific features of the substrate. TA proteins destined for the ER would be transferred to TRC40/Get3, whereas other hydrophobic proteins would have alternative fates. In this view, the evolution of Bag6 (which does not have an obvious yeast homologue) would be for enhanced quality control, whereas yeast may use alternative mechanisms including the recruitment of other chaperones such as Hsp104 and Hsp70, both of which bind to Sgt $2^{78}$. The precise nature of this key sorting step remains an important area of study, and will be greatly aided by structures of complexes combined with structure-based mutagenesis studies. This hydrophobic transfer is likely to be highly coordinated so that exposure of the TMD to the cytosol is minimized.

The substrate recognition problem is in many ways qualitatively different and considerably more complex for post-translational substrates than for co-translational ones. In the cotranslational case, precise positioning of the SRP54 M domain at the ribosome exit tunnel greatly simplifies the recognition problem to one of linear scanning. This not only reduces competition with other factors, but also limits the degrees of freedom for both the substrate and targeting factor. By contrast, post-translational substrates are accessible to a large number of highly abundant chaperones and co-chaperones, all of which primarily interact with proteins on the basis of their hydrophobicity. Nonetheless, effective sorting is achieved among these different factors. TA protein sorting by the TRC may therefore provide a useful paradigm for understanding protein triage among chaperone systems in general.

\section{Protein capture at the ribosome}

Although the existence of a pre-targeting factor helps to explain how substrates might be sorted and loaded onto Get3, the issue of how TA proteins are first captured upon release from the ribosome remains unclear. Some insight into this initial step comes from biochemical analysis in the mammalian system, where the Bag6 complex was observed to interact with ribosomes ${ }^{77}$. Its recruitment there might be mediated by TRC35 or Ubl4A, the yeast homologues of which (Get4 and Get5) were found weakly associated with ribosomes in a proteomic analysis ${ }^{83}$.

Remarkably, recruitment of the Bag6 complex to ribosomes was strongly favoured by the presence of a TMD inside the ribosomal tunnel ${ }^{77}$. The implication of this observation is that the Bag6 complex may be located favorably for initial substrate capture when the substrate is released from the ribosome. But because TA protein release would occur literally a second after the TMD is synthesized, it was unclear how the Bag6 complex could be recruited in time to such ribosomes. This seems to be aided by a TMD-dependent delay in translation termination ${ }^{77}$. 
How the termination of translation might be controlled in a substrate-specific manner remains completely obscure, although it has been observed in other contexts ${ }^{84}$. Similarly, precisely how sequences inside the ribosome could influence events at the surface to promote recruitment of the Bag6 complex remains a mystery. It is possible that the presence of hydrophobic sequences inside the ribosomal tunnel subtly alter ribosome conformation in a manner that is exploited by the Bag6 complex. A similar explanation has been invoked for how SRP might be analogously recruited ${ }^{85,86}$ and how sequences inside the ribosome can influence its interaction with the Sec61 translocon ${ }^{87-89}$. Alternatively, the Bag6 complex might be recruited to ribosomes by signals that are present in the mRNA that encodes the TA protein. Indeed, studies indicate that cis-acting sequences in the TMD-coding region of bacterial membrane protein mRNAs can direct these mRNAs to the plasma membrane ${ }^{90,91}$. The initial capture step by the Bag6 complex remains to be studied in mechanistic detail, as does the apparent regulation of translational termination and the relationship between these two processes.

\section{Targeting and release at the ER}

After a TA protein is successfully loaded onto Get3 by action of the TRC, the resulting Get3-TA protein complex must next be targeted to the ER. In budding yeast, genetic studies have indicated that Get1 and Get2, both of which are multi-spanning ER membrane proteins, are needed for targeting ${ }^{65}$. Furthermore, their ability to form a complex with Get 3 in the absence of other factors ${ }^{61,66}$, suggested that these three proteins could form the minimal factors required for targeting, and possibly insertion into, the ER membrane.

Insight into the role of Get1 and Get2 came from recent reconstitution studies ${ }^{92,93}$. Genetic and biochemical depletion and add-back experiments established that Get1 and Get2 are each indispensable for Get3-dependent TA substrate membrane insertion ${ }^{92,93}$. Remarkably, efficient targeting and insertion could be achieved in proteoliposomes containing only recombinant Get 1 and Get2 at physiological concentrations ${ }^{92}$. Thus, Get1 and Get2 are both necessary and sufficient for the membrane-associated events of TA protein targeting and insertion.

The availability of a simple reconstituted system using completely purified, recombinant components permitted a detailed analysis of how these two membrane proteins interact with, and regulate the function of, Get $3^{92}$. Interaction analysis illustrated that Get1 and Get2 associate via their membrane domains, and that they each interact with Get3 via their prominent (non-homologous) cytosolic domains ${ }^{92,93}$. The unusual feature of a receptor that interacts with Get 3 in two different ways suggested that these two interactions serve distinct functions - targeting of the Get3-TA protein complex to the ER, followed by substrate release at the ER membrane. This indeed proved to be the case, as revealed by a combination of structural and functional studies.

Insight into both steps was provided by structures of the complexes that form between Get3 and the cytosolic Get1 and Get2 receptor fragments (FIG. 5) ${ }^{92,94}$. The structure of the Nterminal end of the Get 2 cytosolic fragment bound to a Get3-ADP• $\mathrm{AlF}_{4}{ }^{-}$complex showed two Get 2 fragments bound to equivalent sites on opposite faces of the 'closed' Get 3 dimer. Importantly, the Get3 hydrophobic groove was intact and accessible, with the N-terminal ends of Get 2 tethered to the membrane by a long flexible linker. A Get1-Get2 complex containing a structure-based mutation in Get 2 that disrupts binding to Get3, was defective for TA protein insertion at the membrane ${ }^{92}$. These observations suggested that Get2 functions to recruit the Get3-TA protein targeting complex to the membrane.

The structure of nucleotide-free Get3 bound to the Get1 cytosolic fragment revealed two Get1 fragments bound to equivalent sites on opposite faces of the 'open' Get3 dimer (FIG. 
5) ${ }^{92,94}$. Strikingly, each Get 1 coiled-coil inserts itself between the two Get3 subunits to completely disrupt the closed dimer interface. This observation immediately suggested that Get1 functions to release substrate from Get3. Consistent with this, functional analysis showed that Get1, but not Get2, promotes substrate release ${ }^{92,93}$. Moreover, Get1 was unable to promote substrate release from an ATPase-deficient Get3 variant (D57N), suggesting that it functions on a Get3-TA substrate complex in which the ATP has already been hydrolysed.

The crystal structures also provided key insights into how targeting and substrate release are coordinated by the two receptor subunits. The Get 1 and Get2 binding sites on Get3 are partially overlapping, and interaction analyses showed that the receptor subunits compete for binding to Get $3^{92}$, consistent with a sequential handover mechanism (FIG. 5). A complex of Get 3 bound simultaneously to portions of Get 2 and Get 1 can be detected at high concentrations by NMR, and may represent the transient intermediate during handover ${ }^{94}$. Taken together, these studies suggest a model in which Get2 recruits the Get3-TA substrate targeting complex, with Get3 in a closed dimer conformation, and subsequently transfers it to Get1, which drives substrate release by disrupting the composite hydrophobic groove and stabilizing the open state of Get3.

The stoichiometry of the Get1-Get2 receptor complex remains to be established. The simplest possibility in view of the crystal structures and the symmetric Get3 dimer is that two Get 1 and two Get 2 subunits form a heterotetrameric assembly. The resulting highavidity interaction of two Get1 subunits with the Get3-TA substrate complex would facilitate substrate release at physiological concentrations. Nevertheless, a heterodimeric receptor is also plausible, with Get 2 binding to one side of the Get 3 heterodimer and Get 1 binding to the other. Evidence that this mechanism could work is suggested by the finding that artificially heterodimerized Get1-Get2 cytosolic domains can mediate substrate release in vitro ${ }^{93}$.

This critical step of releasing a substrate from its tightly bound targeting factor at the correct place and time is a problem faced by all targeting pathways. In the TA protein pathway, substrate release is first obligatorily 'primed' by nucleotide hydrolysis, whereas the actual release is promoted by the Get3-Get1 interaction ${ }^{92,93}$. This two-step mechanism is similar in concept, albeit different in details, with the SRP-mediated co-translational insertion pathway. Here, substrate bound to SRP54 is released in two successive steps, one involving nucleotide and the second involving receptor interaction. The nucleotide-dependent step is GTP binding to both SRP and its receptor to allow targeting ${ }^{95,96}$. The second step is a GTPdependent interaction between SRP and the SRP receptor that results in structural rearrangements that expose the M-domain-signal sequence module to facilitate release to the translocon ${ }^{97}$.

\section{The elusive insertion step}

Virtually nothing is known about how TA substrates are inserted into the ER membrane. Following release from Get3, the substrate must avoid improper interactions (in particular, aggregation) and insert into the membrane bilayer in the correct orientation. On the basis of the rigid interaction between Get1 and Get3, the TMD is presumably released parallel to and abutting the bilayer surface. From this position, insertion requires the hydrophobic TMD to cross the polar head groups of the phospholipids and reach the hydrophobic membrane core. This could occur 'spontaneously' (that is, without direct assistance from any factors), or the Get1/2 complex could chaperone the TA protein into the membrane (FIG. 6). Although in vitro studies show that less hydrophobic TMDs can insert spontaneously into liposomes ${ }^{44,51}$, most TA proteins cannot [Au: so does this support the latter model?]. The mechanistic 
basis of this final step awaits additional studies, but some insight can be gleaned from experiments done in the co-translational system.

A type I membrane protein containing a single N-terminal TMD, a short, luminal domain and an extensive cytosolic C-terminal domain can be efficiently targeted to the membrane surface via the SRP pathway, but subsequent insertion fails in the absence of the Sec61 complex $^{98}$. This indicates that simply targeting a hydrophobic TMD to the membrane surface is insufficient for insertion, and that the Sec61 complex has a crucial role. On the basis of structural and functional analysis, this crucial function is twofold ${ }^{99-101}$. First, Sec61 seems to directly recognize substrate TMDs via a specific-binding site within its membrane domain. Second, this binding site also serves as a 'lateral gate' that provides TMDs direct access to the lipid bilayer. Thus, the TMD takes a route through the centre of Sec61 to bypass the phospholipid headgroups that otherwise preclude facile access to the hydrophobic core of the membrane.

Applying these principles to the TA protein pathway, it is attractive to speculate that Get1 and Get2, both of which are multi-spanning membrane proteins, interact directly with the TA protein's TMD to chaperone it into the bilayer. Such a recognition event could provide an additional layer of proofreading, as has been ascribed to the Sec61 complex ${ }^{102-104}$. More importantly, it would explain how the TMD efficiently accesses the hydrophobic core of the bilayer with minimal possibility of 'off-pathway' events such as aggregation or inappropriate interactions. One speculative model for how 'chaperoning' could be achieved via coupled conformational changes in the Get1-Get2-Get3 complex is depicted in (FIG. 6). Alternatively, Get1-Get2 could distort the lipid bilayer in their vicinity to facilitate TMD insertion. The biochemical strategies used to study Sec61-mediated insertion in the cotranslational pathway $98,101,105-107$ will clearly be useful in determining the insertion mechanism of the TA protein pathway. However, distinguishing between what can happen in a simplified system and what does happen in a physiological context may be challenging as the role of Get1-Get 2 in insertion might simply be to accelerate an already favourable reaction, and any consequences may only be apparent in a highly crowded context reflective of the in vivo situation.

\section{Factor recycling}

After substrate has been released, the Get3-Get1 complex must dissociate so that Get3 can be recycled back to the cytosol and vacate Get1 for the next substrate. The first clue for how this might be accomplished came from early studies that showed ATP-dependent release of TRC40 from the $\mathrm{ER}^{55}$. Structural studies provided the second clue. The crystal structure of nucleotide-free Get 3 bound to the cytosolic fragment of Get1 revealed the stable, highaffinity 'post-insertion' complex ${ }^{92,94}$. In this open dimer conformation, the conserved hairpin loop of Get1 inserts into the Get3 active site. This interaction is both sterically and electrostatically incompatible with ATP binding, suggesting that the high intracellular concentration of free ATP could be utilized to displace Get 3 from Get 1 after substrate release. Consistent with this, interaction studies showed that ATP binding could quantitatively disrupt the Get3-Get1 interaction ${ }^{92-94}$. This recycling mechanism contrasts with the co-translational pathway, in which, after substrate release, the SRP-SRP receptor complex is dissociated by GTP hydrolysis ${ }^{108}$.

After release from Get1, what prevents Get3-ATP from re-binding to Get2 in a 'dead-end' complex that cannot recruit a new TA substrate? Previous studies identified Get3 mutations that disrupt ATP-dependent binding to Get $4{ }^{79}$. Remarkably, these mutations map to the overlapping Get1- and Get2-binding site on Get3. Thus, by competing for the same site as the Get 1 and Get 2 receptor complex, Get 4 binding could sequester the recycled Get3-ATP 
complex in the cytosol and promote another round of substrate loading by TRC. This model is consistent with the observation that distinct Get1-Get2-Get3 and Get3-Get4-Get5 complexes can be isolated from fractionated yeast ${ }^{66}$, and provides an elegant mechanism for spatially regulating Get3 activity in the cytosol and at the ER membrane.

\section{The ATPase cycle}

Biochemical, genetic and structural studies of the various steps in the TA protein pathway have begun to clarify the role of ATP binding and hydrolysis by Get 3 in the insertion cycle. As is the case for SRP in the co-translational pathway, the overarching theme is that nucleotide state directly influences the conformation of Get3, which in turn regulates interactions with the TA substrate, targeting co-factors and receptors at the ER membrane. Some of these interactions subsequently change the nucleotide state. This allows Get 3 to proceed undirectionally through its cycle of conformational changes and thereby selectively bind substrate in the cytosol and release it at the membrane.

Under physiological conditions, Get3 in the cytosol is probably in an ATP-bound closed state $^{92}$. The closed conformation preferentially incorporates into the TRC owing to the nucleotide-dependence of the Get3-Get4 interaction ${ }^{79,93}$. Thus, substrate loading onto Get3 via the TRC requires ATP binding. Once loaded, the TA substrate bridges the helical domains across the hydrophobic groove of Get3. This locks Get3 into a closed conformation, and traps nucleotide in the dimer interface. It is possible that substrate binding stimulates ATP hydrolysis by Get3, which would weaken its interaction with Get4 and promote disengagement from TRC. This would generate a 'committed' ADP-bound Get3TA substrate complex that is stabilized in a closed conformation by the tightly bound substrate.

This targeting complex would be captured at the membrane by Get2, and transferred to Get1. Although targeting seems 'agnostic' to the nucleotide state of Get3, the subsequent transfer reaction absolutely requires ATP to have been hydrolysed ${ }^{92,93}$. This is probably because the binding site for Get1 is partially buried in the fully closed ATP-bound state of Get $3^{92}$. Get1 binding causes Get 3 to fully open, thereby favouring substrate release. Once Get3 opens, the ADP is no longer trapped and probably dissociates rapidly. The rebinding of ATP to Get3 dissociates it from Get1. This effectively means that Get1 acts as a nucleotide exchange factor that displaces ADP (via opening of the Get3 dimer) and allows replacement with ATP.

Whereas most parts of the ATPase cycle have strong experimental support, the timing of ATP hydrolysis remains unclear. It must occur at a point after substrate binding to Get 3 and before interaction with Get1. Although it is attractive to posit that hydrolysis stimulated by either substrate or Get 2 interaction provides an additional checkpoint, this may not be necessary. In fact, a slow rate of intrinsic hydrolysis might provide a mechanism for kinetic proofreading. In this model, loosely bound substrates would dissociate before hydrolysis, thereby preventing their membrane-localized release by Get1. This might reduce inappropriate targeting of mitochondrial TA proteins (which generally have less hydrophobic TMDs than ER-directed TA proteins) $)^{47,49,76}$ to improve overall fidelity of sorting. Similar kinetic proofreading mechanisms have been uncovered in the SRP pathway to maximize sorting efficiency of an otherwise promiscuous interaction between SRP and various proteins ${ }^{109}$.

\section{Future challenges and perspectives}

Since the discovery of the TA protein insertion pathway in 2007, rapid advances have been made through the application of genetic, biochemical and structural approaches. Over the 
past five years all of the core components have been identified, and a general mechanistic understanding of the pathway from ribosome to the ER is now in hand. But the details of many key steps that take place in the cytosol and at the membrane remain a mystery. For example, how does TRC selectively interact with cytosolic ribosomes that contain a TMD in the exit channel? Structural studies are needed to identify the ribosomal binding site of the TRC, and to determine how the TRC senses the presence of a TMD in the exit channel. After this initial capture step, what is the mechanism for TA substrate transfer from TRC to Get3? Although crystal structures exist for Get4 and portions of Get5 and Sgt2 ${ }^{79,110-112,}$ mechanistic insight awaits structural analysis of the intact TRC. More broadly, how does the TRC sort different hydrophobic substrates between its multiple hydrophobic-region-binding factors (including the chaperones Bag6, Sgt2, Get3, Hsps and possibly others)? This critical checkpoint determines the fate of the hydrophobic substrate - insertion into the ER membrane (via Get3), insertion into the mitochondrial outer membrane (by an unknown mechanism), or ubiquitylation (in a process involving Bag6) and proteosomal degradation for misfolded membrane proteins. Defining the mechanism of this process is therefore an important future goal.

The biochemical and structural framework established over the past few years also sets the stage for detailed mechanistic studies of events at the ER membrane. Determining the structure and organization of the Get1-Get2 receptor complex will be critical for understanding insertion. Is the receptor a stable heterodimeric, heterotetrameric or higher order assembly? Or are there temporal variations in stoichiometry and subunit composition? Similarly, the order and timing of Get3-substrate interactions with the receptor have not been directly established. Most significantly, virtually nothing is known about how the TA substrate inserts into the bilayer after its release from Get3. Does it insert spontaneously? Or is it actively chaperoned by the conserved TMDs of Get 1 and Get2? Answers to these questions will require high-resolution structural analysis of Get1-Get2-Get3 complexes, trapped at different stages of this cycle. This promises to be technically challenging, but the goal is in reach now that robust expression systems for functional Get1 and Get2 proteins are in hand.

Finally, there may be much to learn by studying TA protein biogenesis in other organisms. The recent discovery of a conserved Get 3 orthologue in archaea indicates that the posttranslational TA pathway is more broadly conserved than previously appreciated ${ }^{113,114}$. No obvious sequence homologues have been identified for other cytosolic components (for example, Bag6, Sgt2, Get4 or Get5), but functional data are consistent with the presence of an orthologous integral membrane receptor in archaea ${ }^{114}$. If such a receptor exists in archaea, it shares only limited sequence homology with the yeast receptor subunits, Get1 and Get2. There are also intriguing evolutionary differences between the yeast and mammalian pathways. The absence of a Bag6 homologue in yeast suggests increasing complexity in the pre-targeting machinery of higher eukaryotes. And whereas the human WRB protein shows sequence and functional homology to yeast Get $1^{115}$, no obvious sequence homologue to Get2 has been found in higher eukaryotes. Thus, identification and characterization of components in the archaeal and higher eukaryotic pathways promises new insight into the mechanism of TA protein targeting and insertion.

\section{Acknowledgments}

Research in the Hegde laboratory is supported by the Medical Research Council, UK. Research in the Keenan laboratory is supported by grants from the US National Institutes of Health (R01 GM086487), the Camille and Henry Dreyfus Foundation and the Edward Mallinckrodt, Jr Foundation. The authors thank members of their laboratories and other colleagues for helpful discussions. 


\section{Glossary terms}

\section{RIBOSOME EXIT TUNNEL}

\section{CHAPERONES}

HSP70

THYLAKOID

TRANSLOCON

SNARE
An internal channel in the large subunit of the ribosome through which the nascent polypeptide travels before emerging into the cytosol. Various factors bound to the ribosome surface can affect the folding and/or targeting of the nascent polypeptide as it emerges from the exit tunnel

A large group of proteins that facilitate the folding, assembly, transport and degradation of non-native polypeptides by minimizing inappropriate interactions

An ubiquitous family of $\sim 70 \mathrm{kDa}$ heat-shock proteins that serve as molecular chaperones to regulate polypeptide folding, translocation and degradation

A specialized membrane-bound compartment that contains the photosynthetic pigments in photosynthetic organisms

A membrane channel associated with the transport of polypeptides into or across cellular membranes

(soluble $\mathrm{N}$-ethylmaleimide-sensitive fusion protein attachment protein (SNAP) receptor). A family of membrane-tethered coiledcoil proteins that regulate fusion reactions and target specificity in vesicle trafficking. Can be divided into v-SNAREs and t-SNAREs on the basis of their localization

\section{Bibliography}

1. Wallin E, von Heijne G. Genome-wide analysis of integral membrane proteins from eubacterial, archaean, and eukaryotic organisms. Protein Sci. 1998; 7:1029-1038. [PubMed: 9568909]

2. Fagerberg L, Jonasson K, von Heijne G, Uhlen M, Berglund L. Prediction of the human membrane proteome. Proteomics. 2010; 10:1141-1149. [PubMed: 20175080]

3. White SH, von Heijne G. Transmembrane helices before, during, and after insertion. Curr Opin Struct Biol. 2005; 15:378-386. [PubMed: 16043344]

4. White SH, von Heijne G. How translocons select transmembrane helices. Annu Rev Biophys. 2008; 37:23-42. [PubMed: 18573071]

5. Chacinska A, Koehler CM, Milenkovic D, Lithgow T, Pfanner N. Importing mitochondrial proteins: machineries and mechanisms. Cell. 2009; 138:628-644. [PubMed: 19703392]

6. Heiland I, Erdmann R. Biogenesis of peroxisomes. Topogenesis of the peroxisomal membrane and matrix proteins. FEBS J. 2005; 272:2362-2372. [PubMed: 15885087]

7. Inaba T, Schnell DJ. Protein trafficking to plastids: one theme, many variations. Biochem J. 2008; 413:15-28. [PubMed: 18537794]

8. Shao S, Hegde RS. Membrane Protein Insertion at the Endoplasmic Reticulum. Annu Rev Cell Dev Biol. 2010

9. Palade G. Intracellular aspects of the process of protein synthesis. Science. 1975; 189:347-358. [PubMed: 1096303]

10. Wickner W, Schekman R. Protein translocation across biological membranes. Science. 2005; 310:1452-1456. [PubMed: 16322447]

11. Rapoport TA. Protein translocation across the eukaryotic endoplasmic reticulum and bacterial plasma membranes. Nature. 2007; 450:663-669. [PubMed: 18046402]

12. Blobel G, Dobberstein B. Transfer of proteins across membranes. I. Presence of proteolytically processed and unprocessed nascent immunoglobulin light chains on membrane-bound ribosomes of murine myeloma. J Cell Biol. 1975; 67:835-851. [PubMed: 811671] 
13. Blobel G, Dobberstein B. Transfer of proteins across membranes. II. Reconstitution of functional rough microsomes from heterologous components. J Cell Biol. 1975; 67:852-862. [PubMed: 811672]

14. Walter P, Ibrahimi I, Blobel G. Translocation of proteins across the endoplasmic reticulum. I. Signal recognition protein (SRP) binds to in-vitro-assembled polysomes synthesizing secretory protein. J Cell Biol. 1981; 91:545-550. [PubMed: 7309795]

15. Hann BC, Walter P. The signal recognition particle in S. cerevisiae. Cell. 1991; 67:131-144. [PubMed: 1655273]

16. Gorlich D, Prehn S, Hartmann E, Kalies KU, Rapoport TA. A mammalian homolog of SEC61p and SECYp is associated with ribosomes and nascent polypeptides during translocation. Cell. 1992; 71:489-503. [PubMed: 1423609]

17. Hartmann E, et al. Evolutionary conservation of components of the protein translocation complex. Nature. 1994; 367:654-657. [PubMed: 8107851]

18. Jungnickel B, Rapoport TA, Hartmann E. Protein translocation: common themes from bacteria to man. FEBS Lett. 1994; 346:73-77. [PubMed: 8206162]

19. Poritz MA, et al. An E. coli ribonucleoprotein containing 4.5S RNA resembles mammalian signal recognition particle. Science. 1990; 250:1111-1117. [PubMed: 1701272]

20. Stuart RA, Cyr DM, Craig EA, Neupert W. Mitochondrial molecular chaperones: their role in protein translocation. Trends Biochem Sci. 1994; 19:87-92. [PubMed: 8160272]

21. Soll J, Tien R. Protein translocation into and across the chloroplastic envelope membranes. Plant Mol Biol. 1998; 38:191-207. [PubMed: 9738967]

22. Rapoport TA, Matlack KE, Plath K, Misselwitz B, Staeck O. Posttranslational protein translocation across the membrane of the endoplasmic reticulum. Biol Chem. 1999; 380:1143-1150. [PubMed: 10595576]

23. Mori H, Cline K. Post-translational protein translocation into thylakoids by the Sec and DeltapHdependent pathways. Biochim Biophys Acta. 2001; 1541:80-90. [PubMed: 11750664]

24. Ma C, Agrawal G, Subramani S. Peroxisome assembly: matrix and membrane protein biogenesis. J Cell Biol. 2011; 193:7-16. [PubMed: 21464226]

25. Keenan RJ, Freymann DM, Stroud RM, Walter P. The signal recognition particle. Annu Rev Biochem. 2001; 70:755-775. [PubMed: 11395422]

26. Grudnik P, Bange G, Sinning I. Protein targeting by the signal recognition particle. Biol Chem. 2009; 390:775-782. [PubMed: 19558326]

27. Walter P, Blobel G. Purification of a membrane-associated protein complex required for protein translocation across the endoplasmic reticulum. Proc Natl Acad Sci U S A. 1980; 77:7112-7116. [PubMed: 6938958]

28. Walter P, Blobel G. Signal recognition particle contains a 7S RNA essential for protein translocation across the endoplasmic reticulum. Nature. 1982; 299:691-698. [PubMed: 6181418]

29. Halic M, et al. Structure of the signal recognition particle interacting with the elongation-arrested ribosome. Nature. 2004; 427:808-814. [PubMed: 14985753]

30. Zopf D, Bernstein HD, Johnson AE, Walter P. The methionine-rich domain of the 54 kd protein subunit of the signal recognition particle contains an RNA binding site and can be crosslinked to a signal sequence. EMBO J. 1990; 9:4511-4517. [PubMed: 1702385]

31. High S, Dobberstein B. The signal sequence interacts with the methionine-rich domain of the 54kD protein of signal recognition particle. J Cell Biol. 1991; 113:229-233. [PubMed: 1849137]

32. Gilmore R, Walter P, Blobel G. Protein translocation across the endoplasmic reticulum. II. Isolation and characterization of the signal recognition particle receptor. J Cell Biol. 1982; 95:470-477. [PubMed: 6292236]

33. Meyer DI, Krause E, Dobberstein B. Secretory protein translocation across membranes-the role of the "docking protein'. Nature. 1982; 297:647-650. [PubMed: 7088152]

34. Simon SM, Blobel G. A protein-conducting channel in the endoplasmic reticulum. Cell. 1991; 65:371-380. [PubMed: 1902142]

35. Deshaies RJ, Schekman R. A yeast mutant defective at an early stage in import of secretory protein precursors into the endoplasmic reticulum. J Cell Biol. 1987; 105:633-645. [PubMed: 3305520] 
36. Becker T, et al. Structure of monomeric yeast and mammalian Sec61 complexes interacting with the translating ribosome. Science. 2009; 326:1369-1373. [PubMed: 19933108]

37. Menetret JF, et al. The structure of ribosome-channel complexes engaged in protein translocation. Mol Cell. 2000; 6:1219-1232. [PubMed: 11106759]

38. Beckmann R, et al. Architecture of the protein-conducting channel associated with the translating 80S ribosome. Cell. 2001; 107:361-372. [PubMed: 11701126]

39. Ulbrandt ND, Newitt JA, Bernstein HD. The E. coli signal recognition particle is required for the insertion of a subset of inner membrane proteins. Cell. 1997; 88:187-196. [PubMed: 9008159]

40. Ott M, et al. Mba1, a membrane-associated ribosome receptor in mitochondria. EMBO J. 2006; 25:1603-1610. [PubMed: 16601683]

41. Nilsson R, van Wijk KJ. Transient interaction of cpSRP54 with elongating nascent chains of the chloroplast-encoded D1 protein; 'cpSRP54 caught in the act'. FEBS Lett. 2002; 524:127-133. [PubMed: 12135754]

42. Kutay U, Hartmann E, Rapoport TA. A class of membrane proteins with a C-terminal anchor. Trends Cell Biol. 1993; 3:72-75. [PubMed: 14731773]

43. Kutay U, Ahnert-Hilger G, Hartmann E, Wiedenmann B, Rapoport TA. Transport route for synaptobrevin via a novel pathway of insertion into the endoplasmic reticulum membrane. EMBO J. 1995; 14:217-223. Demonstrates that a model TA protein is inserted into the ER via an SRPand Sec-independent post-translational process that requires ATP hydrolysis and proteasesensitive microsomal factor(s). [PubMed: 7835332]

44. Brambillasca $S$, et al. Transmembrane topogenesis of a tail-anchored protein is modulated by membrane lipid composition. EMBO J. 2005; 24:2533-2542. [PubMed: 15973434]

45. Yabal M, et al. Translocation of the $\mathrm{C}$ terminus of a tail-anchored protein across the endoplasmic reticulum membrane in yeast mutants defective in signal peptide-driven translocation. J Biol Chem. 2003; 278:3489-3496. [PubMed: 12446686]

46. Steel GJ, Brownsword J, Stirling CJ. Tail-anchored protein insertion into yeast ER requires a novel posttranslational mechanism which is independent of the SEC machinery. Biochemistry. 2002; 41:11914-11920. [PubMed: 12269836]

47. Beilharz T, Egan B, Silver PA, Hofmann K, Lithgow T. Bipartite signals mediate subcellular targeting of tail-anchored membrane proteins in Saccharomyces cerevisiae. J Biol Chem. 2003; 278:8219-8223. [PubMed: 12514182]

48. Kalbfleisch T, Cambon A, Wattenberg BW. A bioinformatics approach to identifying tail-anchored proteins in the human genome. Traffic. 2007; 8:1687-1694. [PubMed: 17892534]

49. Kriechbaumer V, et al. Subcellular distribution of tail-anchored proteins in Arabidopsis. Traffic. 2009; 10:1753-1764. [PubMed: 19843281]

50. Colombo SF, Longhi R, Borgese N. The role of cytosolic proteins in the insertion of tail-anchored proteins into phospholipid bilayers. J Cell Sci. 2009; 122:2383-2392. [PubMed: 19531581]

51. Brambillasca S, Yabal M, Makarow M, Borgese N. Unassisted translocation of large polypeptide domains across phospholipid bilayers. J Cell Biol. 2006; 175:767-777. [PubMed: 17130291]

52. Abell BM, Rabu C, Leznicki P, Young JC, High S. Post-translational integration of tail-anchored proteins is facilitated by defined molecular chaperones. J Cell Sci. 2007; 120:1743-1751. [PubMed: 17456552]

53. Abell BM, Pool MR, Schlenker O, Sinning I, High S. Signal recognition particle mediates posttranslational targeting in eukaryotes. Embo J. 2004; 23:2755-2764. [PubMed: 15229647]

54. Abell BM, et al. Tail-anchored and signal-anchored proteins utilize overlapping pathways during membrane insertion. J Biol Chem. 2003; 278:5669-5678. [PubMed: 12464599]

55. Stefanovic S, Hegde RS. Identification of a targeting factor for posttranslational membrane protein insertion into the ER. Cell. 2007; 128:1147-1159. Reports the discovery of the mammalian TA protein pathway and identification of the TRC40 ATPase as the central cytosolic component. [PubMed: 17382883]

56. Favaloro V, Spasic M, Schwappach B, Dobberstein B. Distinct targeting pathways for the membrane insertion of tail-anchored (TA) proteins. J Cell Sci. 2008; 121:1832-1840. [PubMed: 18477612] 
57. Kurdi-Haidar B, et al. Isolation of the ATP-binding human homolog of the arsA component of the bacterial arsenite transporter. Genomics. 1996; 36:486-491. [PubMed: 8884272]

58. Chen CM, Misra TK, Silver S, Rosen BP. Nucleotide sequence of the structural genes for an anion pump. The plasmid-encoded arsenical resistance operon. J Biol Chem. 1986; 261:15030-15038. [PubMed: 3021763]

59. Mukhopadhyay R, Ho YS, Swiatek PJ, Rosen BP, Bhattacharjee H. Targeted disruption of the mouse Asnal gene results in embryonic lethality. FEBS Lett. 2006; 580:3889-3894. [PubMed: 16797549]

60. Auld KL, et al. The conserved ATPase Get3/Arr4 modulates the activity of membrane-associated proteins in Saccharomyces cerevisiae. Genetics. 2006; 174:215-227. [PubMed: 16816426]

61. Schuldiner M, et al. Exploration of the function and organization of the yeast early secretory pathway through an epistatic miniarray profile. Cell. 2005; 123:507-519. [PubMed: 16269340]

62. Kao G, et al. ASNA-1 positively regulates insulin secretion in C. elegans and mammalian cells. Cell. 2007; 128:577-587. [PubMed: 17289575]

63. Shen J, Hsu CM, Kang BK, Rosen BP, Bhattacharjee H. The Saccharomyces cerevisiae Arr4p is involved in metal and heat tolerance. Biometals. 2003; 16:369-378. [PubMed: 12680698]

64. Ho Y, et al. Systematic identification of protein complexes in Saccharomyces cerevisiae by mass spectrometry. Nature. 2002; 415:180-183. [PubMed: 11805837]

65. Schuldiner M, et al. The GET complex mediates insertion of tail-anchored proteins into the ER membrane. Cell. 2008; 134:634-645. Shows that GET proteins identified in references 60 and 61 are part of the TA pathway in yeast. Get3 is shown to be the TRC40 orthologue, and Get1 and Get2 shown to be an ER-localized GET receptor complex. [PubMed: 18724936]

66. Jonikas MC, et al. Comprehensive characterization of genes required for protein folding in the endoplasmic reticulum. Science. 2009; 323:1693-1697. [PubMed: 19325107]

67. Costanzo M, et al. The genetic landscape of a cell. Science. 2010; 327:425-431. [PubMed: 20093466]

68. Bozkurt G, et al. Structural insights into tail-anchored protein binding and membrane insertion by Get3. Proc Natl Acad Sci USA. 2009; 106:21131-21136. [PubMed: 19948960]

69. Hu J, Li J, Qian X, Denic V, Sha B. The crystal structures of yeast Get3 suggest a mechanism for tail-anchored protein membrane insertion. PLoS ONE. 2009; 4:e8061. [PubMed: 19956640]

70. Mateja A, et al. The structural basis of tail-anchored membrane protein recognition by Get3. Nature. 2009; 461:361-366. [PubMed: 19675567]

71. Suloway CJ, Chartron JW, Zaslaver M, Clemons WM Jr. Model for eukaryotic tail-anchored protein binding based on the structure of Get3. Proc Natl Acad Sci U S A. 2009; 106:1484914854. [PubMed: 19706470]

72. Yamagata A, et al. Structural insight into the membrane insertion of tail-anchored proteins by Get3. Genes Cells. 2010; 15:29-41. References 68-72 describe the crystal structure of fungal Get3 in different nucleotide-bound states. Reference 70 reveals a large, hydrophobic groove in the $\mathrm{Mg}^{2+} \mathrm{ADP} \cdot \mathrm{AlF}_{4}{ }^{-}$-bound complex. References 68 and 70 implicate this groove as the TMDbinding site by using mutational and biophysical analysis. [PubMed: 20015340]

73. Keenan RJ, Freymann DM, Walter P, Stroud RM. Crystal structure of the signal sequence binding subunit of the signal recognition particle. Cell. 1998; 94:181-191. [PubMed: 9695947]

74. Janda CY, et al. Recognition of a signal peptide by the signal recognition particle. Nature. 2010

75. Hainzl T, Huang S, Merilainen G, Brannstrom K, Sauer-Eriksson AE. Structural basis of signalsequence recognition by the signal recognition particle. Nat Struct Mol Biol. 2011; 18:389-391. [PubMed: 21336278]

76. Borgese N, Brambillasca S, Colombo S. How tails guide tail-anchored proteins to their destinations. Curr Opin Cell Biol. 2007; 19:368-375. [PubMed: 17629691]

77. Mariappan $\mathrm{M}$, et al. A ribosome-associating factor chaperones tail-anchored membrane proteins. Nature. 2010; 466:1120-1124. [PubMed: 20676083]

78. Wang F, Brown EC, Mak G, Zhuang J, Denic V. A chaperone cascade sorts proteins for posttranslational membrane insertion into the endoplasmic reticulum. Mol Cell. 2010; 40:159-171. References 77 and 78 describe a cytosolic protein complex that captures TA proteins after 
synthesis and transfers them to TRC40/Get3 for subsequent targeting to the ER membrane. [PubMed: 20850366]

79. Chartron JW, Suloway CJM, Zaslaver Ma, Clemons WM. Structural characterization of the Get4/ Get5 complex and its interaction with Get3. Proc Natl Acad Sci USA. 2010; 107:12127-12132. [PubMed: 20554915]

80. Hessa T, et al. Protein targeting and degradation are coupled for elimination of mislocalized proteins. Nature. 2011; 475:394-397. [PubMed: 21743475]

81. Wang Q, et al. A ubiquitin ligase-associated chaperone holdase maintains polypeptides in soluble states for proteasome degradation. Mol Cell. 2011; 42:758-770. [PubMed: 21636303]

82. Minami R, et al. BAG-6 is essential for selective elimination of defective proteasomal substrates. J Cell Biol. 2010; 190:637-650. [PubMed: 20713601]

83. Fleischer TC, Weaver CM, McAfee KJ, Jennings JL, Link AJ. Systematic identification and functional screens of uncharacterized proteins associated with eukaryotic ribosomal complexes. Genes Dev. 2006; 20:1294-1307. [PubMed: 16702403]

84. Cao J, Geballe AP. Coding sequence-dependent ribosomal arrest at termination of translation. Mol Cell Biol. 1996; 16:603-608. [PubMed: 8552088]

85. Berndt U, Oellerer S, Zhang Y, Johnson AE, Rospert S. A signal-anchor sequence stimulates signal recognition particle binding to ribosomes from inside the exit tunnel. Proc Natl Acad Sci U S A. 2009; 106:1398-1403. [PubMed: 19164516]

86. Bornemann T, Jockel J, Rodnina MV, Wintermeyer W. Signal sequence-independent membrane targeting of ribosomes containing short nascent peptides within the exit tunnel. Nat Struct Mol Biol. 2008; 15:494-499. [PubMed: 18391966]

87. Liao S, Lin J, Do H, Johnson AE. Both lumenal and cytosolic gating of the aqueous ER translocon pore are regulated from inside the ribosome during membrane protein integration. Cell. 1997; 90:31-41. [PubMed: 9230300]

88. Lin PJ, Jongsma CG, Pool MR, Johnson AE. Polytopic membrane protein folding at L17 in the ribosome tunnel initiates cyclical changes at the translocon. J Cell Biol. 2011; 195:55-70. [PubMed: 21949410]

89. Lin PJ, Jongsma CG, Liao S, Johnson AE. Transmembrane segments of nascent polytopic membrane proteins control cytosol/ER targeting during membrane integration. J Cell Biol. 2011; 195:41-54. [PubMed: 21949411]

90. Prilusky J, Bibi E. Studying membrane proteins through the eyes of the genetic code revealed a strong uracil bias in their coding mRNAs. Proc Natl Acad Sci U S A. 2009; 106:6662-6666. [PubMed: 19366666]

91. Nevo-Dinur K, Nussbaum-Shochat A, Ben-Yehuda S, Amster-Choder O. Translation-independent localization of mRNA in E. coli. Science. 2011; 331:1081-1084. [PubMed: 21350180]

92. Mariappan M, et al. The mechanism of membrane-associated steps in tail-anchored protein insertion. Nature. 2011; 477:61-66. [PubMed: 21866104]

93. Wang F, Whynot A, Tung M, Denic V. The Mechanism of Tail-Anchored Protein Insertion into the ER Membrane. Mol Cell. 2011; 43:738-750. [PubMed: 21835666]

94. Stefer S, et al. Structural basis for tail-anchored membrane protein biogenesis by the Get3-receptor complex. Science. 2011; 333:758-762. Reference 92 defines the minimal set of factors required for TA protein insertion by biochemical reconstitution using purified, recombinant Get1, Get2, and Get3. References 92 and 94 provide structural snapshots of Get3 bound to cytosolic fragments of Get1 and Get2. References 92 and 93 describe a detailed biochemical analysis of targeting, substrate release and Get3 recycling. [PubMed: 21719644]

95. Egea PF, et al. Substrate twinning activates the signal recognition particle and its receptor. Nature. 2004; 427:215-221. [PubMed: 14724630]

96. Focia PJ, Shepotinovskaya IV, Seidler JA, Freymann DM. Heterodimeric GTPase core of the SRP targeting complex. Science. 2004; 303:373-377. [PubMed: 14726591]

97. Ataide SF, et al. The crystal structure of the signal recognition particle in complex with its receptor. Science. 2011; 331:881-886. [PubMed: 21330537] 
98. Heinrich SU, Mothes W, Brunner J, Rapoport TA. The Sec61p complex mediates the integration of a membrane protein by allowing lipid partitioning of the transmembrane domain. Cell. 2000; 102:233-244. [PubMed: 10943843]

99. Van den Berg B, et al. X-ray structure of a protein-conducting channel. Nature. 2004; 427:36-44. [PubMed: 14661030]

100. Tsukazaki T, et al. Conformational transition of Sec machinery inferred from bacterial SecYE structures. Nature. 2008; 455:988-991. [PubMed: 18923527]

101. Cannon KS, Or E, Clemons WM Jr, Shibata Y, Rapoport TA. Disulfide bridge formation between SecY and a translocating polypeptide localizes the translocation pore to the center of SecY. J Cell Biol. 2005; 169:219-225. [PubMed: 15851514]

102. Flower AM, Doebele RC, Silhavy TJ. PrlA and PrlG suppressors reduce the requirement for signal sequence recognition. J Bacteriol. 1994; 176:5607-5614. [PubMed: 8083155]

103. Osborne RS, Silhavy TJ. PrlA suppressor mutations cluster in regions corresponding to three distinct topological domains. EMBO J. 1993; 12:3391-3398. [PubMed: 8253067]

104. Smith MA, Clemons WM Jr, DeMars CJ, Flower AM. Modeling the effects of prl mutations on the Escherichia coli SecY complex. J Bacteriol. 2005; 187:6454-6465. [PubMed: 16159779]

105. Mothes W, Prehn S, Rapoport TA. Systematic probing of the environment of a translocating secretory protein during translocation through the ER membrane. EMBO J. 1994; 13:3973-3982. [PubMed: 8076593]

106. Martoglio B, Hofmann MW, Brunner J, Dobberstein B. The protein-conducting channel in the membrane of the endoplasmic reticulum is open laterally toward the lipid bilayer. Cell. 1995; 81:207-214. [PubMed: 7736572]

107. Do H, Falcone D, Lin J, Andrews DW, Johnson AE. The cotranslational integration of membrane proteins into the phospholipid bilayer is a multistep process. Cell. 1996; 85:369-378. [PubMed: 8616892]

108. Connolly T, Rapiejko PJ, Gilmore R. Requirement of GTP hydrolysis for dissociation of the signal recognition particle from its receptor. Science. 1991; 252:1171-1173. [PubMed: 1851576]

109. Zhang X, Rashid R, Wang K, Shan SO. Sequential checkpoints govern substrate selection during cotranslational protein targeting. Science. 2010; 328:757-760. [PubMed: 20448185]

110. Chang YW, et al. Crystal structure of Get4-Get5 complex and its interactions with Sgt2, Get3, and Ydj1. J Biol Chem. 2010; 285:9962-9970. [PubMed: 20106980]

111. Bozkurt G, et al. The structure of Get4 reveals an alpha-solenoid fold adapted for multiple interactions in tail-anchored protein biogenesis. FEBS Lett. 2010

112. Chartron JW, Gonzalez GM, Clemons WM Jr. A structural model of SGT2 and its interactions with chaperones and GET4/GET5. J Biol Chem. 2011; 286:34325-34334. [PubMed: 21832041]

113. Borgese N, Righi M. Remote origins of tail-anchored proteins. Traffic. 2010; 11:877-885. [PubMed: 20406421]

114. Sherrill J, Mariappan M, Dominik P, Hegde RS, Keenan RJ. A conserved archaeal pathway for tail-anchored membrane protein insertion. Traffic. 2011; 12:1119-1123. [PubMed: 21658170]

115. Vilardi F, Lorenz H, Dobberstein B. WRB is the receptor for TRC40/Asna1-mediated insertion of tail-anchored proteins into the ER membrane. J Cell Sci. 2011; 124:1301-1307. [PubMed: 21444755]

116. Copic A, et al. Genomewide analysis reveals novel pathways affecting endoplasmic reticulum homeostasis, protein modification and quality control. Genetics. 2009; 182:757-769. [PubMed: 19433630]

\section{Biographies}

Robert Keenan carried out his Ph.D. and postdoctoral research at UCSF working with Robert Stroud and Peter Walter. He then spent five years at Maxygen in Redwood City, California, USA, before moving to the University of Chicago, IL, USA, where he is currently an Associate Professor in the Department of Biochemistry and Molecular Biology. His laboratory studies membrane protein biogenesis. 
Ramanujan Hegde received his M.D. and Ph.D. from UCSF where he worked with Vishu Lingappa. He was then a principal investigator at the National Institutes of Health for twelve years before recently joining the MRC Laboratory of Molecular Biology in Cambridge, UK. His laboratory studies membrane protein biogenesis and quality control. 

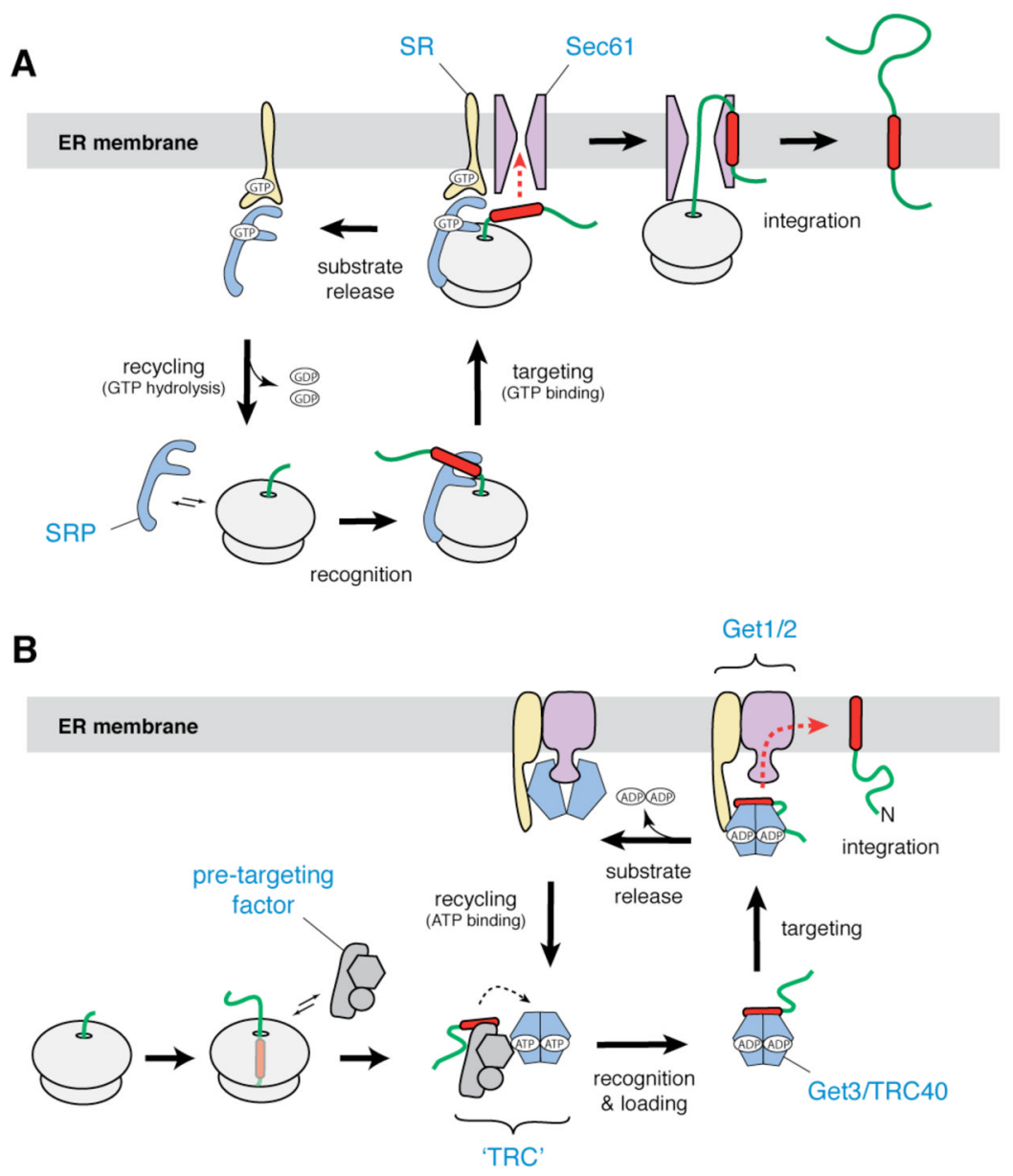

Figure 1. Membrane protein biosynthesis in eukaryotes

a | In the co-translational pathway for insertion of ER membrane proteins, SRP (blue) recognizes the hydrophobic signal peptide (red) of the nascent chain as it emerges from a translating ribosome. The ribosome-nascent chain-SRP complex is targeted to the membrane by a GTP-dependent interaction with the SRP receptor (yellow), resulting in release of the signal peptide and docking of the ribosome-nascent chain complex to the Sec61 translocon (magenta). Translation then resumes, and the nascent polypeptide is inserted into the membrane bilayer. After GTP hydrolysis, SRP is recycled to the cytosol. b | In the post-translational pathway for insertion of tail-anchored (TA) ER membrane proteins, a soluble pre-targeting complex (grey) captures the hydrophobic TMD (red) of the TA substrate after it emerges from the ribosomal exit channel. After loading onto Get3/TRC40 (shown as a blue-green dimer), the TA substrate is delivered to the ER membrane by interaction with the Get1-Get2 receptor complex (yellow and magenta). Upon ATP hydrolysis, the TA substrate is released for insertion into the bilayer. ATP binding recycles Get3/TRC40 back to the cytosol. 


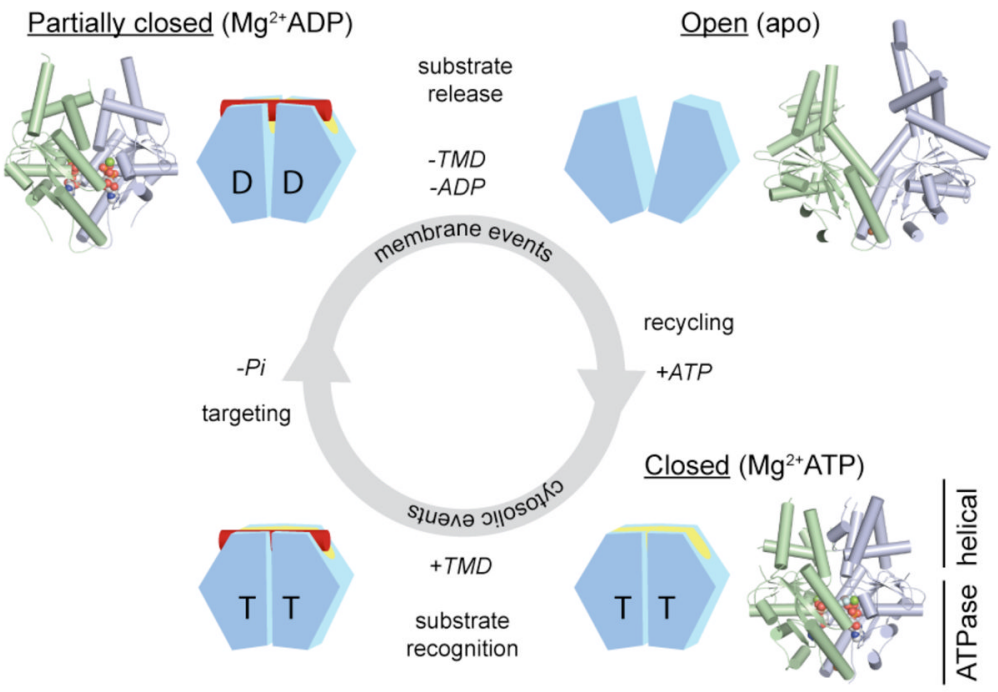

Figure 2. Nucleotide-dependent conformational changes in the Get3 homodimer Each Get3 monomer comprises two distinct regions: an ATPase- and an a-helical subdomain. In the presence of ATP, the Get3 helical subdomains become intimately associated, forming an extended composite hydrophobic groove (see FIG. 3) that recognizes and binds to the TMD of a TA substrate (red). ATP hydrolysis, which occurs at some stage prior to release of the TA substrate at the ER membrane, produces an ADP-bound Get3 homodimer that is partially closed. Following release of the TA substrate and ADP, Get3 shifts back to an open conformation. Subsequently, ATP binding allows recycling of Get3 back to the cytosol in a closed conformation. The insets show crystal structures of the fungal Get3 homodimer in the nucleotide-free (PDB ID 2WOO), $\mathrm{Mg}^{2+} \mathrm{ADP}-$ bound (PDB ID 3IQX) and $\mathrm{Mg}^{2+} \mathrm{ADP} \bullet \mathrm{AlF}_{4}{ }^{-}$-bound (PDB ID 2WOJ) states. 

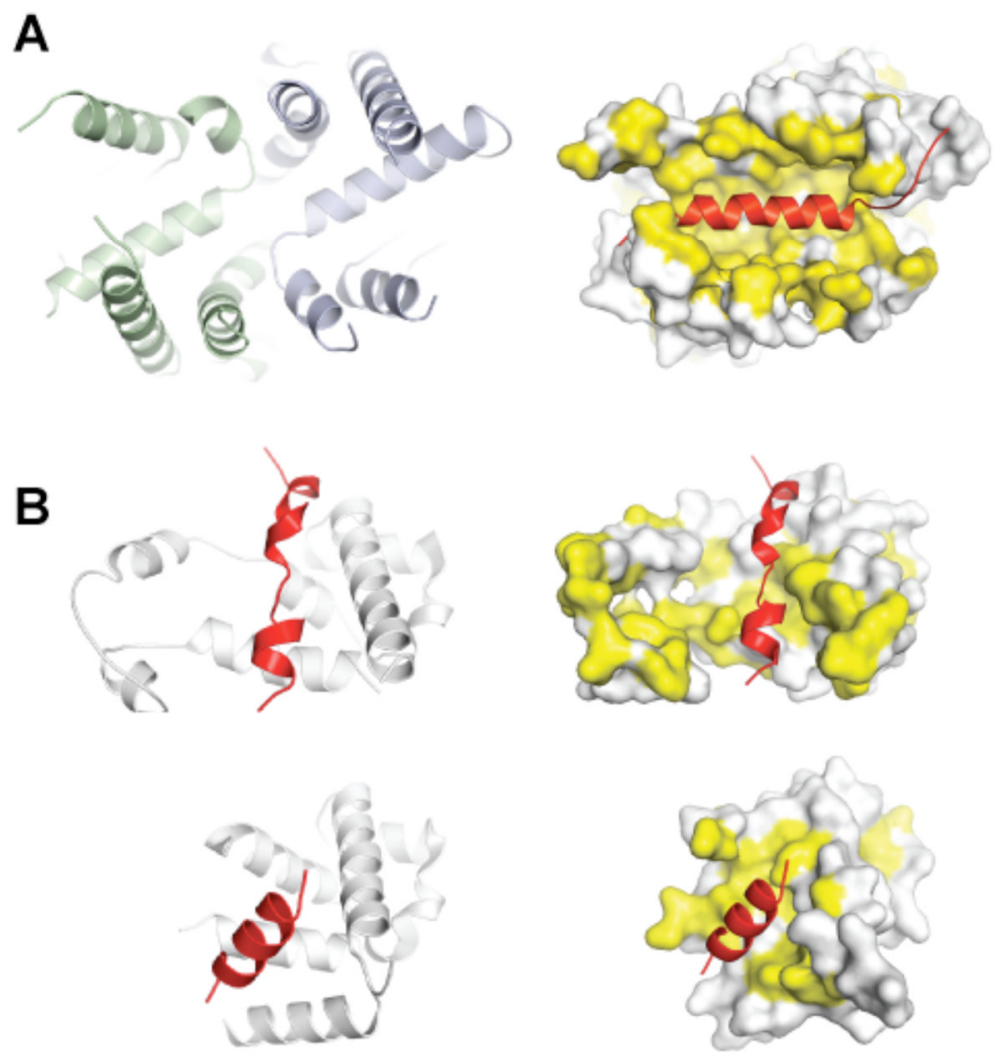

Figure 3. Substrate recognition by the post- and co-translational targeting machinery a A large groove in Get3 is formed by association of the two a-helical subdomains (left panel, green and blue) in the ATP-bound, closed dimer conformation. This composite groove presents a large hydrophobic surface for binding to the TMD of a TA protein substrate. The TA protein Sec61 $\beta$ (shown on the right side in red; PDB ID 1RHZ) is modelled into the groove; hydrophobic surfaces are in yellow. $\mathbf{b} \mid$ Crystal structures of the methionine-rich M-domain of SRP54 bound to a signal peptide (shown in red) (top, PDB ID 3KL4; bottom, PDB ID 3NBD). Note the different, but overlapping peptide binding sites. For both the post-translational TA protein pathway (a) and the co-translational pathway (b), the dynamic properties of these helical, hydrophobic scaffolds probably allows them to accommodate different sequences during targeting. 


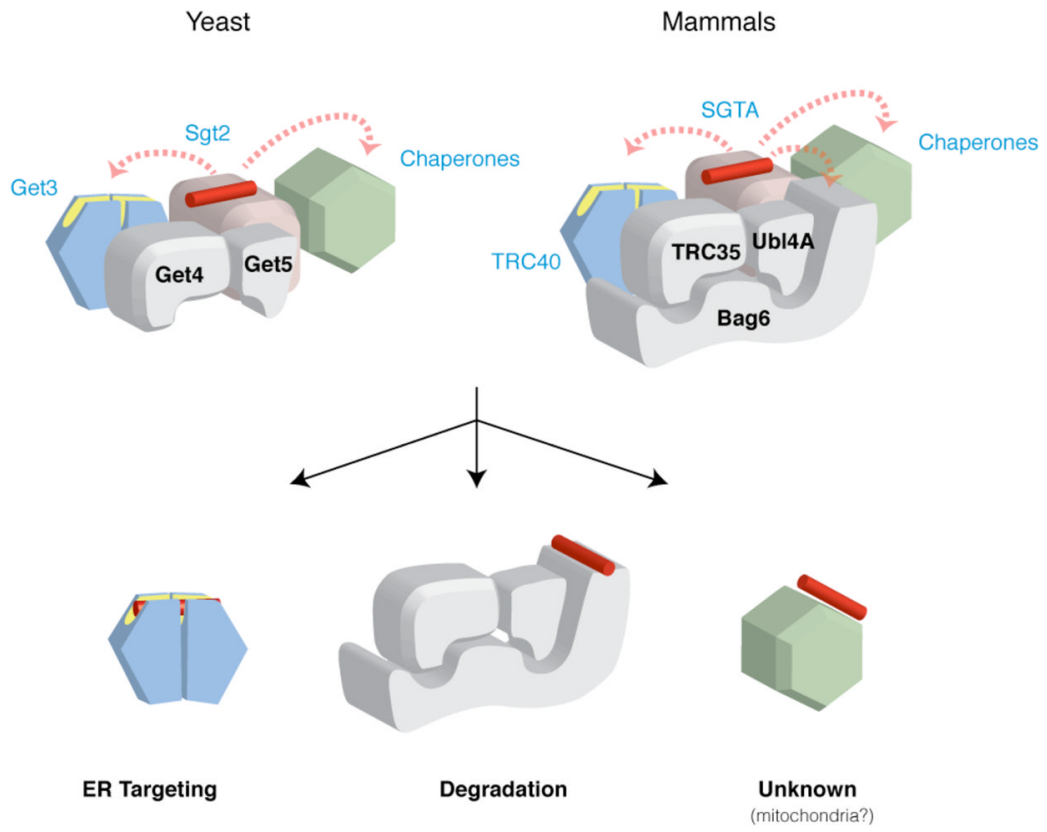

Figure 4. TA protein sorting by the TRC

The TMD recognition complex (TRC) consists of a stable core complex (depicted in grey) and several dynamically associated components. In budding yeast, the TRC core consists of Get4 and Get5, with Get4 recruiting Get3, and Get5 recruiting Sgt2. Sgt2 can additionally recruit other chaperones. In mammals, TRC35 (which is homologous to Get4) and Ubl4A (which is homologous to Get5) are in a complex with Bag6, which probably recruits SGTA (which is homologous to Sgt2). Engagement of the TRC by a substrate (probably bound to Sgt2/SGTA) results in its sorting among any of several potential TMD-binding proteins (dashed arrows). This sorting is presumably dictated by a combination of substrate features and availability of the binding partners. The substrate can therefore emerge from the TRC bound to any of multiple binding partners, each of which imparts a specific downstream fate. Get3/TRC40 association mediates ER targeting, whereas Bag6 binding can recruit an E3 ubiquitin ligase that mediates substrate degradation. The fate of other complexes are not understood but could include targeting to other destinations including the mitochondria. 


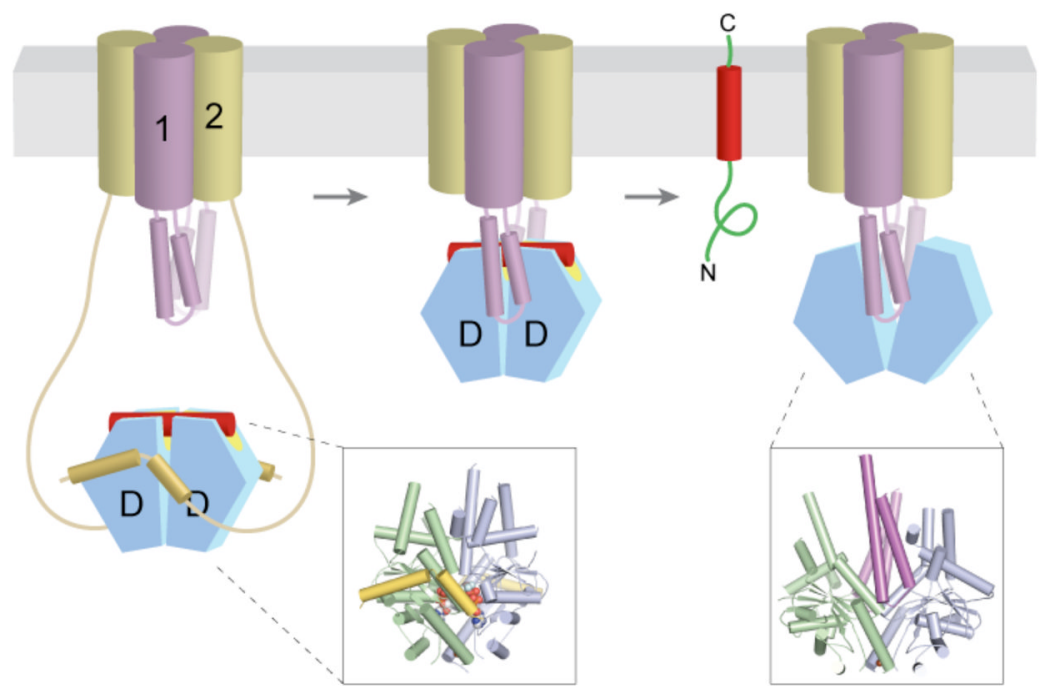

Figure 5. Targeting and substrate release at the ER membrane

Nucleotide (either ADP or ATP) and TA substrate (red)-bound Get3 (blue and green) is captured at the ER membrane by the long, flexible amino termini of Get2 (yellow). After ATP hydrolysis, the Get3-TA substrate complex is transferred to Get1, which wedges open the composite hydrophobic groove to promote TA substrate (and ADP) release. Finally, ATP re-binding dissociates the stable Get1-Get3 post-insertion complex to recycle Get3 back to the cytosol. Although depicted here as a stable heterotetramer, the stoichiometry and subunit composition of the Get1-Get2 receptor complex is not known. The insets show crystal structures of $\mathrm{Mg}^{2+} \mathrm{ADP} \cdot \mathrm{AlF}_{4}{ }^{-}$-bound Get3 in complex with the cytosolic fragment of Get2 (left, PDB ID 3ZS9), and of nucleotide-free Get3 in complex with the cytosolic fragment of Get1 (right, PDB ID 3ZS8). 


\section{Unassisted}

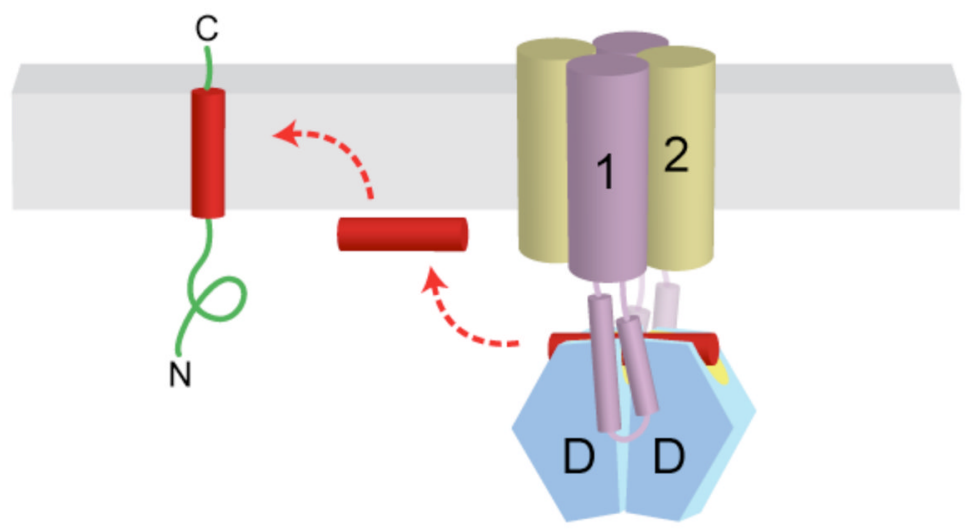

\section{Chaperoned}

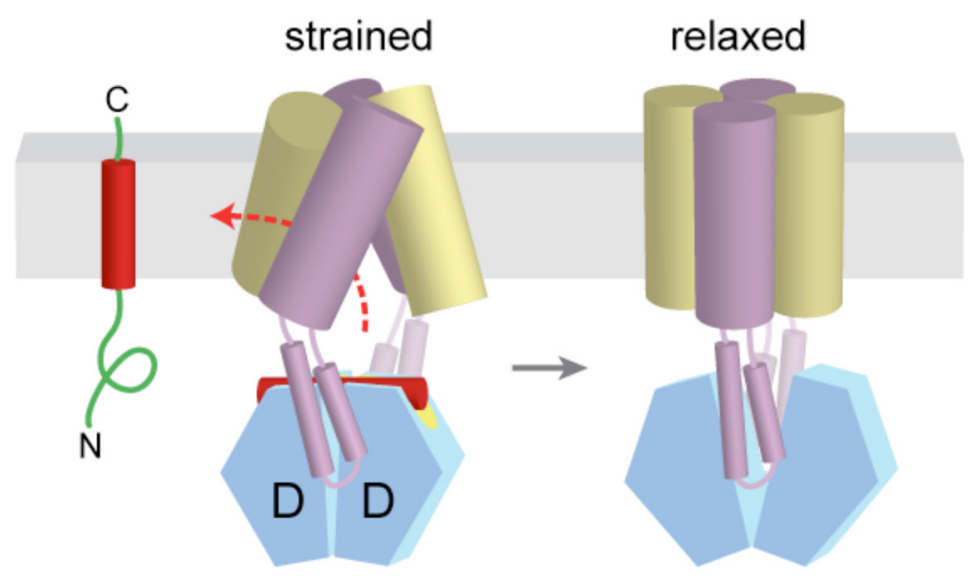

Figure 6. Alternative models for insertion of TA proteins into the ER membrane

a After release from Get3, the TA substrate might transiently associate with the membrane surface before inserting spontaneously into the lipid bilayer. b | Alternatively, the transmembrane domains (TMDs) of Get1 and Get2 may interact directly with the TA substrate to 'chaperone' it into the bilayer. In the model shown here, binding of two Get1 subunits to the partially closed targeting complex results in a 'strained' configuration of the Get1-Get2 receptor complex. This arrangement might provide a hydrophobic gate through which the TMD could diffuse into the bilayer. 'Wedging open' the Get 3 dimer for substrate release would then allow the Get1-Get2 receptor complex to 'relax' back into a low-energy configuration that is sealed off from the cytosol. Thus, conformational changes in Get3 might be coupled to those of the receptor TMDs to promote TA substrate integration. 